\title{
Primary and successive events in the Madden-Julian Oscillation
}

\author{
Adrian J. Matthews* \\ School of Environmental Sciences and School of Mathematics, University of East Anglia, Norwich, UK
}

\begin{abstract}
Conventional analyses of the MJO tend to produce a repeating cycle, such that any particular feature cannot be unambiguously attributed to the current or previous event. We take advantage of the sporadic nature of the MJO and classify each observed Madden-Julian (MJ) event as either primary, with no immediately preceding MJ event, or successive, which does immediately follow a preceding event. 40\% of MJ events are primary events. Precursor features of the primary events can be unambiguously attributed to that event. A suppressed convective anomaly grows and decays in situ over the Indian Ocean, prior to the start of most primary MJ events. An associated mid-tropospheric temperature anomaly destabilises the atmosphere, leading to the generation of the active MJ event. Hence, primary MJ events appear to be thermodynamically triggered by a previous dry period, although stochastic forcing may also be important. Other theories predict that boundary-layer convergence, humidity, propagation of dynamical structures around the Equator, sea surface temperatures, and lateral forcing by extratropical transients may all be important in triggering an event. Although precursor signals from these mechanisms are diagnosed from reanalysis and satellite observational data in the successive MJ events, they are all absent in the primary MJ events. Hence, it appears that these apparent precursor signals are part of the MJO once it is established, but do not play a role in the spontaneous generation of the MJO. The most frequent starting location of the primary events is the Indian Ocean, but over half of them start elsewhere, from the maritime continent to the western Pacific. Copyright (C) 2008 Royal Meteorological Society
\end{abstract}

KEY WORDS MJO; intraseasonal oscillation; spontaneous generation mechanism

Received 25 April 2007; Revised 16 January 2008; Accepted 21 January 2008

\section{Introduction}

The Madden-Julian Oscillation (MJO) is the dominant mode of variability on intraseasonal time-scales in the tropical atmosphere. As such, it has been comprehensively studied over the last three decades. For a full review, see Zhang (2005) and Lau and Waliser (2005). Its basic characteristics are the eastward propagation of large-scale precipitation anomalies, accompanied by an associated dynamical and thermodynamical structure, over the warm pool region, from the Indian Ocean through the maritime continent to the western Pacific. A single cycle of the MJO lasts between 30 and 60 days. The MJO affects the timing of the onset and modulates the intraseasonal variability of the monsoon systems of the Indian subcontinent (Goswami, 2005), southeast Asia (Hsu, 2005), Australia and Indonesia (Wheeler and McBride, 2005), America (Mo and Paegle, 2005) and Africa (Matthews, 2004a). Hence, it significantly affects the agriculture in these regions and the lives of the more than one billion people who live there. In addition, there is an extratropical component of the MJO that affects weather outside of the tropics, for example, along the

* Correspondence to: Adrian J. Matthews, School of Environmental Sciences, University of East Anglia, Norwich, NR4 7TJ, UK.

E-mail: a.j.matthews@uea.ac.uk western coast of the United States (Bond and Vecchi, 2003).

Despite its importance to the climate system, the MJO is poorly predicted by numerical weather prediction models, although statistically based empirical forecast models are now having some success (Waliser, 2005). Part of this problem is that the mechanisms for the generation and maintenance of the MJO are not fully understood.

A compounding issue is that there is no clear, universally accepted definition or metric of the MJO, such as there is for El Niño. This is partly because the MJO has an inherently complex structure, it is sporadic in nature and has a wide broad-band signal, and it exhibits considerable seasonal dependence and interannual variability. It can even be argued that the MJO is not really an oscillation at all, but can best be described as a sequence of individual, discrete Madden-Julian (MJ) events (Salby and Hendon, 1994; Hendon and Salby, 1994; Yano et al., 2004), the timing and duration of which may or may not be related to previous events.

Several theories have been put forward to explain the generation and maintenance mechanisms behind the MJO (review in Wang, 2005). These include theories based on convective destabilisation, boundary-layer dynamics, pre-moistening of the mid-troposphere, propagation of MJO anomalies around the entire equatorial belt, air-sea 
interaction, and lateral triggering by equatorward-propagating extratropical systems. More detailed discussions of these mechanisms are given in section 5 .

Generally, it is difficult to diagnose and distinguish between these different generation mechanisms from observational data because of the quasi-periodic nature of the MJO. Observational analyses based on conventional compositing or regression techniques (e.g. Knutson and Weickmann, 1987; Kiladis and Weickmann, 1992; Hendon and Salby, 1994; Matthews, 2000) produce a cyclical MJO, where the events of the preceding MJO cycle run seamlessly into the next cycle. Hence, any particular feature of interest could be attributed to the current or the previous or even the next MJ event, and cause and effect cannot be unambiguously determined. This is another reason why an accepted definition of the MJO has been hard to come by. With a quasi-periodic phenomenon there is some arbitrariness about where to define the 'start' of the cycle, though the generally accepted start is assumed to be the initiation of convection over the Indian Ocean.

In this paper, we take advantage of the sporadic nature of the MJO and distinguish between primary and successive MJ events. Primary MJ events have no preceding cycle of the MJO. They may be the first in a sequence of MJ events, or they may be single, isolated MJ events. Successive MJ events follow on from a previous cycle of the MJO, from either a primary MJ event, or another successive event. The primary events and successive events will be analysed separately. Composites based on the successive events will be like previous observational composite studies of the canonical MJO, where one MJO cycle merges into the next, and individual features cannot be unambiguously attributed to one cycle or the next. The focus will be on the analysis of the primary MJ events. This will provide the opportunity to identify genuine trigger or precursor signals that are not associated with a previous MJ event, and will help to answer the question of how the MJO starts again once it has decayed. Also, the analysis of these primary events will allow us to unambiguously diagnose where MJ events start.

The data used in this study are described in section 2 . Section 3 describes the methodology used to define the MJO, and section 4 introduces the primary and successive $\mathrm{MJ}$ events and examines the starting location for the MJO. The search for precursor signals to the MJO is described in section 5. Conclusions are presented in section 6 .

\section{Data}

Outgoing long-wave radiation (OLR) data were used as a proxy for deep convective precipitation in the tropics. The data were from the daily mean, gridded, interpolated dataset of Liebmann and Smith (1996), from 1 June 1974 to 31 December 2005, with missing data from 17 March 1978 to 31 December 1978 due to satellite failure. Wind, temperature and specific humidity fields were extracted as daily means from the National Centers for Environmental Prediction-National Center for Atmospheric Research (NCEP-NCAR) reanalysis (Kalnay et al., 1996), from 1 June 1974 to 31 December 2005. The Microwave Sounding Unit (MSU) mid-tropospheric (channel 3/4) temperatures were also used, as daily means from 1 January 1979 to 31 December 1993 (Spencer et al., 1990). All the data described above were on a $2.5^{\circ}$ latitude $\times 2.5^{\circ}$ longitude grid. Sea surface temperature (SST) from the NOAA Optimum Interpolation (OI v2) dataset (Reynolds et al., 2002) were extracted from 29 October 1981 to 31 December 2005. These were on a $1^{\circ}$ latitude $\times 1^{\circ}$ longitude grid. The data were available as weekly means, which were then linearly interpolated to daily means.

For each dataset, the annual cycle (mean and first three annual harmonics) was subtracted from each grid point to produce anomaly fields. These were then passed through a wide 20-200-day band-pass Lanczos filter, to isolate the intraseasonal signal. This wide band-pass filter preserves the signal of individual isolated MJ events without introducing spurious maxima and minima before and after the events, as a more conventional narrower (e.g. 30-70-day) filter does (Matthews, 2000). The filter employed 241 symmetric weights. Hence, the first and last 120 days of each dataset were lost during the filter process, and the missing data in the middle of the filtered OLR dataset ran from 17 November 1977 to 30 April 1979.

\section{Methodology}

Multivariate indices for the MJO, based on both the precipitation and dynamical signals, have recently been proposed as metrics for the MJO (e.g. Wheeler and Hendon, 2004). However, the purpose of this study is to search for precursor signals to the MJO to isolate the mechanisms that may be important for the generation of individual MJ events. Hence, it is appropriate to use a univariate definition of the MJO based solely on its convection signal, and then to search for precursor signals in other independent variables.

Following Matthews (2000), a conventional empirical orthogonal function (EOF) analysis was performed on the 20-200-day filtered OLR anomalies in the tropical region $\left(25^{\circ} \mathrm{S}\right.$ to $\left.25^{\circ} \mathrm{N}\right)$. The EOFs were calculated from the covariance matrix and were not rotated. EOF1 (Figure 1(a)) captures the dipole phase of the MJO with active convection (negative OLR anomalies) over the Indian Ocean and suppressed convection (positive OLR anomalies) over the western Pacific. The quadrature phase of the MJO, with enhanced convection over Indonesia is captured by EOF2 (Figure 1(b)). EOF1 and EOF2 account for $7.8 \%$ and $6.7 \%$ of the 20-200-day filtered tropical OLR variance, respectively. They are well separated from EOF3 by the criteria of North et al. (1982).

The spatial structures of EOF1 and EOF2 were then projected back onto the filtered daily OLR anomaly 
(a)

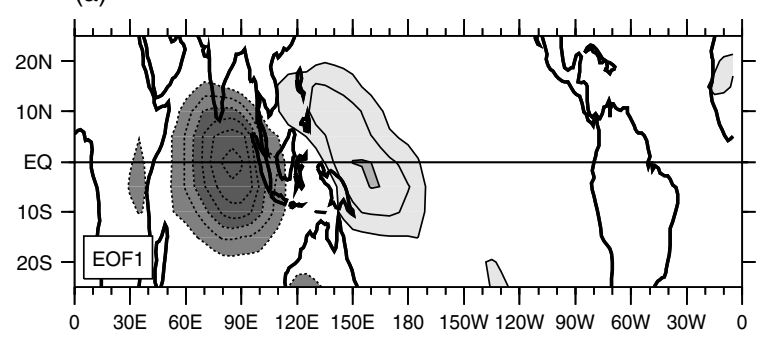

(b)

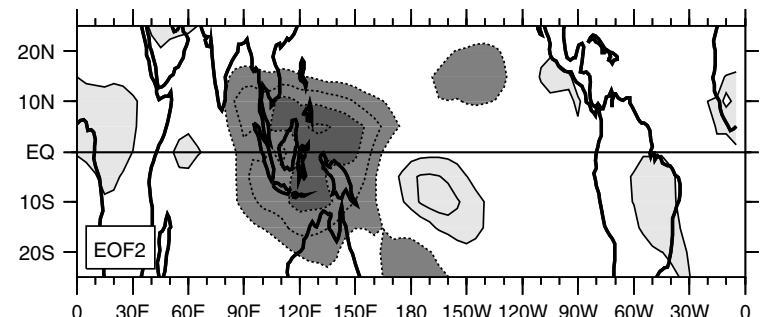

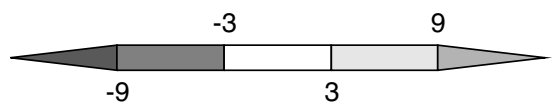

Figure 1. (a) EOF1 and (b) EOF2 of 20-200-day filtered tropical OLR anomalies. The contour interval is $3 \mathrm{~W} \mathrm{~m}^{-2}$, negative contours are dotted, and the zero contour is omitted.

(a)

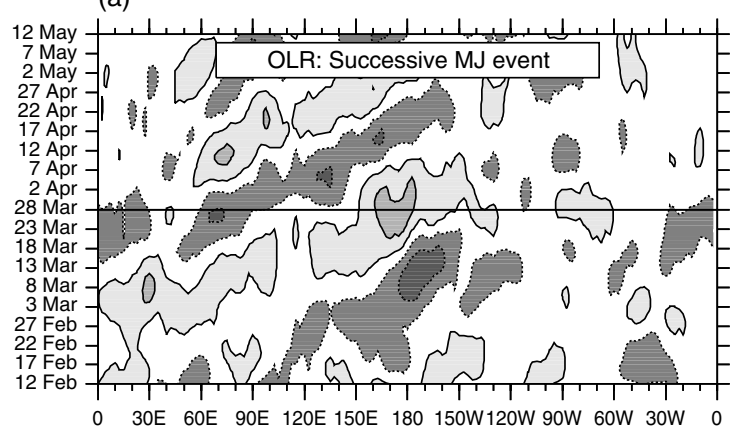

(c)

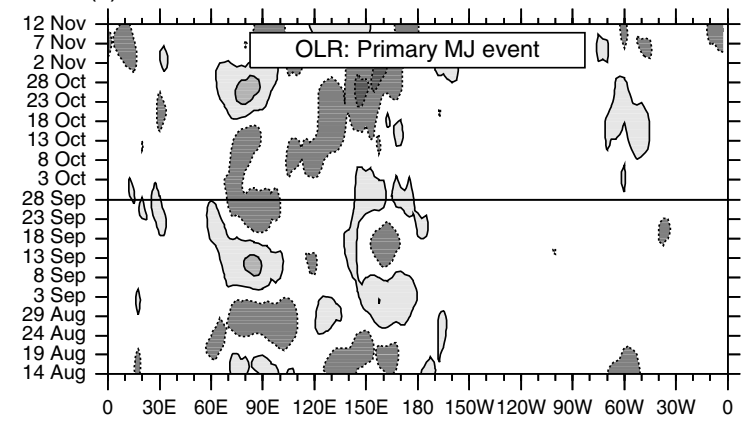

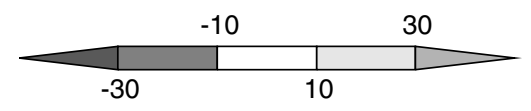

(b)

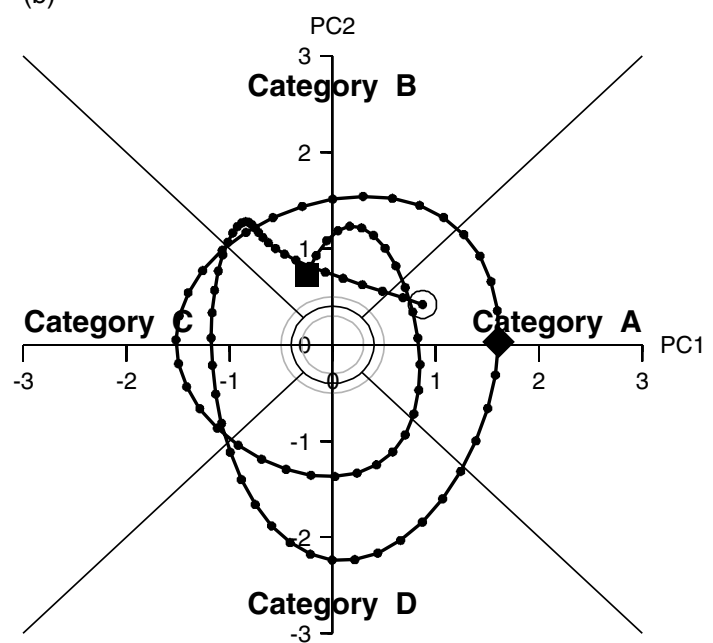

(d)

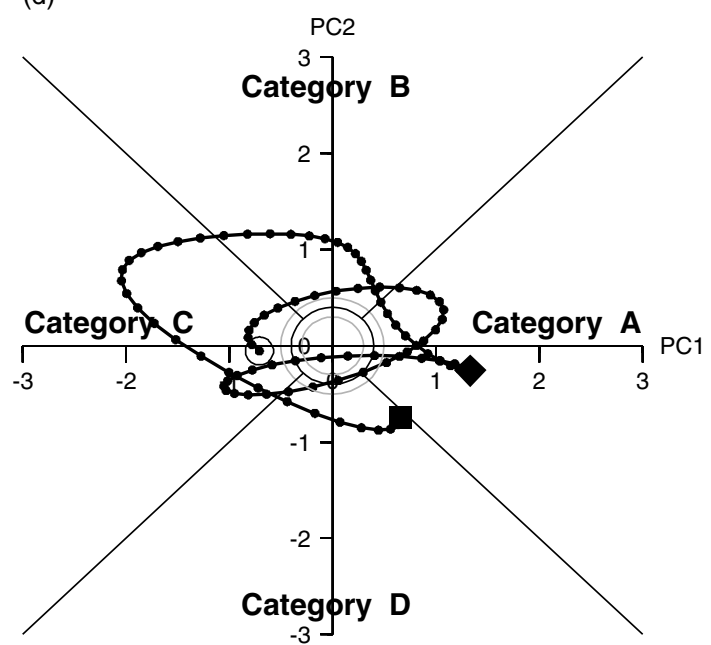

Figure 2. (a) Hovmöller diagram of 20-200-day filtered OLR anomalies averaged from $10^{\circ} \mathrm{S}$ to $10^{\circ} \mathrm{N}$, for a 91-day period from 12 February 1992 to 12 May 1992, showing a successive MJ event. The contour interval is $20 \mathrm{~W} \mathrm{~m}^{-2}$, negative contours are dotted and the first positive contour is at $10 \mathrm{~W} \mathrm{~m}^{-2}$. (b) Corresponding (PC1,PC2) phase-space diagram. The first, central and last days are shown by an open circle, a filled diamond, and a filled square, respectively. See text for details. (c) and (d) are as (a) and (b), but for the period from 14 August 1992 to 12 November 1992, showing a primary MJ event.

maps to create the principal component time series PC1 and $\mathrm{PC} 2$. PC1 and $\mathrm{PC} 2$ have a maximum correlation of 0.55 at a lag of 10 days (approximately a quarter cycle). Hence, the state of the MJO on any given day is described by the PC1 and PC2 values. For example, during the 91-day period from 12 February 1992 to 12 May 1992, just over two MJO cycles can be seen by the eastward-propagating negative and positive OLR anomalies in the Hovmöller diagram of Figure 2(a). The corresponding 91-day PC1 and PC2 time series are shown in a (PC1,PC2) phase space in Figure 2(b) (Matthews, 2000). The first day (12 February 1992) is shown by a large open circle at coordinates $(\mathrm{PC} 1=0.87, \mathrm{PC} 2=$ 0.42 ). Subsequent days are shown by closed circles, and 
as time increases, the locus of these points describes just over two anticlockwise circuits around the origin, corresponding to the two MJO cycles in Figure 2(a).

Using this phase-space representation, the MJO can be divided into four categories (Hall et al., 2001). Category $\mathrm{A}$ is defined as the quadrant centred on the positive PC1 axis (Figure 2(b)). Days that fall into category A will tend to have OLR anomaly maps that are similar to EOF1 (Figure 1(a)), with enhanced precipitation over the Indian Ocean and reduced precipitation over the western Pacific. Category B is the quadrant centred on the positive $\mathrm{PC} 2$ axis (wet over Indonesia); category $\mathrm{C}$ is centred on the negative PC1 axis (wet over western Pacific and dry over Indian Ocean), and category D is centred on the negative PC2 axis (dry over Indonesia).

A further constraint was then applied to the amplitude of the MJO, $A=\sqrt{P C 1^{2}+P C 2^{2}}$. Days when the amplitude of the MJO was below a critical value $(A<$ $A_{\mathrm{c}}$ ) were assigned to a category $\mathrm{N}$ (no MJO). A critical value of $A_{\mathrm{c}}=0.4$ was chosen subjectively, as when $A<$ 0.4 coherent eastward propagation of OLR anomalies on a Hovmöller diagram could not generally be seen. Hence, days that fell within a circle of radius $A_{\mathrm{c}}$ centred on the origin in the $(\mathrm{PC} 1, \mathrm{PC} 2)$ phase-space diagram
(Figure 2(b)) were assigned to category N. In a few cases, the locus of the (PC1,PC2) trajectory would just graze the inside of the circle of radius $A_{\mathrm{c}}$, and the MJO state would unrealistically flip from (say) category A, to N, then back to $\mathrm{A}$ in a few days. To prevent this, a buffer zone was created, with two circles of radius $A_{\text {low }}=0.3$ and $A_{\text {high }}=0.5$. To change from category A, B, C or D to $\mathrm{N}$, the locus would have to cross the smaller circle to $A<A_{\text {low }}$. To change from category $\mathrm{N}$ to $\mathrm{A}, \mathrm{B}, \mathrm{C}$ or $\mathrm{D}$, the locus would have to cross the larger circle to $A>A_{\text {high }}$. The main results were not sensitive to the exact values of $A_{\mathrm{c}}$ or the buffer zone.

This procedure reduces the MJO to a string of letters chosen from the set $[A, B, C, D, N]$, one letter for each day. Finally, each segment of time spent in a particular category (e.g. 9 continuous days in category B) was replaced by a single instance of the relevant letter (i.e. one ' $\mathrm{B}$ '). Assuming for the moment that an MJ event begins with active convection over the Indian Ocean (category A), a complete MJO cycle is represented by the string 'ABCD'. The 91-day period in Figure 2(b) is represented by the string $A B C D A B C D A B$, and the full 31-year record of MJOs is represented by the 1133-character string in Table I, split into years for ease

Table I. The MJO from 29 September 1974 to 2 September 2005 in string representation. Primary (successive) MJ events starting over the Indian Ocean are shown in bold, e.g. NABCD (italics, e.g. $D A B C D$ ).

\begin{tabular}{|c|c|}
\hline 1974 & $\mathrm{BNCBN} D A B C D A$ \\
\hline 1975 & $B C D A B N D A B C D A B C D C D N B A B C D A B C N D A D N A B C N A D C B N A B C D$ \\
\hline 1976 & $A B C D A B C N C N A B C D A D C B A D C B A N C D A B C D A B C D A B C D A N$ \\
\hline 1977 & BCDABCDABCDABCDNABNCDNABNDABCNDANBNCDAN \\
\hline \multicolumn{2}{|r|}{ 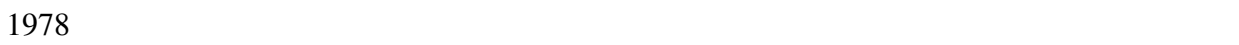 } \\
\hline 1979 & ABCDABA $D A B C D A D A B C D A N A B C D A$ \\
\hline 1980 & BADCBADNBCDABCDNCDANBCNADCBCDCNABCDANCBA \\
\hline 1981 & BCBCDABCDANCBNCNABCDABCNABNABCD \\
\hline 1982 & $A B C D A B C D A N C D A B C D A N B C D A B C N A N C D A B C D A B C D A B$ \\
\hline 1983 & CDANCNADABCNCDABCBANDCBADADCBCDABNABCNADC \\
\hline 1984 & BABABANCDABADCNBNCNADANCBANCNCNABCDABABC \\
\hline 1985 & $D A B C D C N A B C D N A D C B C D A D N C N A D C B N D A B C N C D$ \\
\hline 1986 & $A B C D C B N A B C D A B C D A B C D A B C B N D N B N D C N A B C D C D$ \\
\hline 1987 & ABABCBCDABNDNBCDABCDABANCNADABCBNADCDABCNABCD \\
\hline 1988 & $A B C D A B C D A B C B C D A N C N A D N A B C N A B C D$ \\
\hline 1989 & $A B C D N B C D A B C D A B A N B C D N A B C D A B C N C N A D N C B A B N B C D A$ \\
\hline 1990 & $B C D A B C D A B C D A B A B C D N A B C D C B A B C D A B C D A B C D$ \\
\hline 1991 & $A B C D N D A B A B C D A B C D A N A D C B C N C D A B N C B A N C D A B$ \\
\hline 1992 & $C D A B C D A B C D A B C D \mathbf{N A B C D A N C N A D N C B A D C N A B C D A N A B C}$ \\
\hline 1993 & DABCDCBADNBCDADNCDABCDANDABCNANCNBANCDANCNABC \\
\hline 1994 & DNBCNDABN $D A B C D C N B C D A N C D A B C D N A D N B C D N D A B C D$ \\
\hline 1995 & $A B C D A B C D A B C D A B C D A B C D A D A B C N D A B C N$ \\
\hline 1996 & DABANCDABCDABCDABCDABCDANCBCDABCDABCD \\
\hline 1997 & NABCDABCDABCDABCNBABCDCDADANBC \\
\hline 1998 & DANCDAN $D A B C D A B C B C D A B N D A D N B C N A B C D C N B N D C B$ \\
\hline 1999 & NDABCDABCDADNCBCDADCBNCNABCDADABCDABCD \\
\hline 2000 & NBNABCDABABCDNANCNBCDABCDADNCBCDABCDCD \\
\hline 2001 & NBABCDNBCNDANABCDANCBCNDABCDADABCDABCDC \\
\hline 2002 & DABNCBNABNCDABCDABCNADABCDCDABCDABCDAB \\
\hline 2003 & $C D N A D C B C D A B C D A B C D A N B C D A B N C B C D A B C D A N A B C$ \\
\hline 2004 & DABCN $D A B C D A B C N B C D A D N A B C B N A N B C N A B C D A D A B C D A B$ \\
\hline 2005 & $C D C D C D N A B C D A B C D C N A N C D A B C D A$ \\
\hline
\end{tabular}


of reading. The missing data from 17 November 1977 to 30 April 1979 are represented by the single ' $N$ ' at the end of 1977. There were very similar numbers of instances of each of the four MJO categories: 251 instances of 'A', 237 of ' $B$ ', 257 of ' $C$ ', and 234 of ' $D$ '. There were 154 instances of ' $\mathrm{N}$ ', though this depended on the exact value chosen for the threshold $A_{\mathrm{c}}$. There were 117 complete $\mathrm{MJO}$ cycles (instances of 'ABCD') in the full record.

\section{Classification of MJ events}

\subsection{Successive MJ events}

We are now in a position to distinguish between and define primary and successive MJ events. Still assuming that an MJ event begins in category A (wet over the Indian Ocean), then a successive MJ event is defined by the string 'DABCD', representing the final category ' $D$ ' of the previous cycle, followed by a full cycle 'ABCD'. The example presented in Figure 2(a,b) was a successive MJ event. The start time of the MJ event $(t=0)$ is taken as the day in category A when PC1 is at its maximum. This was on 28 March 1992 (horizontal line in Figure 2(a)), and is indicated by the filled diamond in the phase-space diagram (Figure 2(b)). The preceding MJ event can clearly be seen before this.

There are 82 successive MJ events (instances of 'DABCD') in the full record (Table I). The composite Hovmöller diagram of tropical OLR anomalies, averaged over all 82 successive events (Figure 3(a)), clearly shows the current MJO cycle with precipitation peaking (negative OLR anomaly) over the Indian Ocean $\left(80^{\circ} \mathrm{E}\right)$ at $t=0$, and its subsequent eastward propagation. This is preceded by a previous MJ event, shown by the eastward propagating positive OLR anomalies at negative lags. The composite (PC1,PC2) phase-space diagram (Figure 3(b)) shows the clear anticlockwise propagation from category $\mathrm{D}$ of the previous event into category $\mathrm{A}$ of the current event. Again, the start time $(t=0)$ is indicated by the filled diamond in the phase-space diagram (Figure 3(b)).

Some simple information on the number of consecutive MJ events can also be extracted from Table I. The longest run was 6 consecutive events (an instance of 'DABCDABCDABCDABCDABCDABCD'), in 1994-1995. Once this has been discarded, there were 3 separate runs of quadruple events, then 9 separate triple events, then 14 double events, and 9 single events. (a)

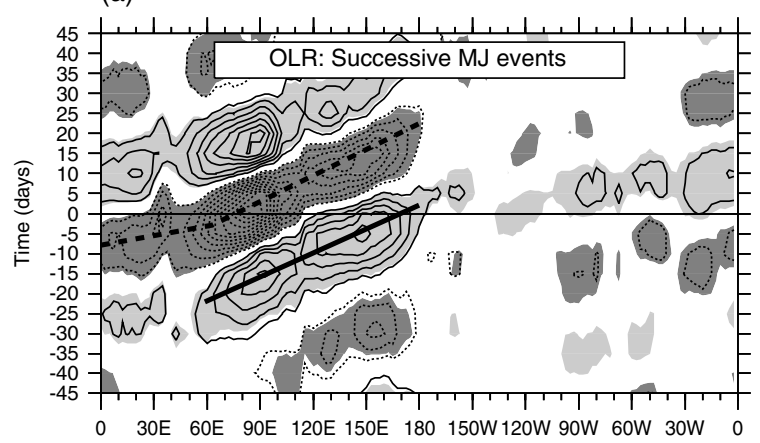

(b)

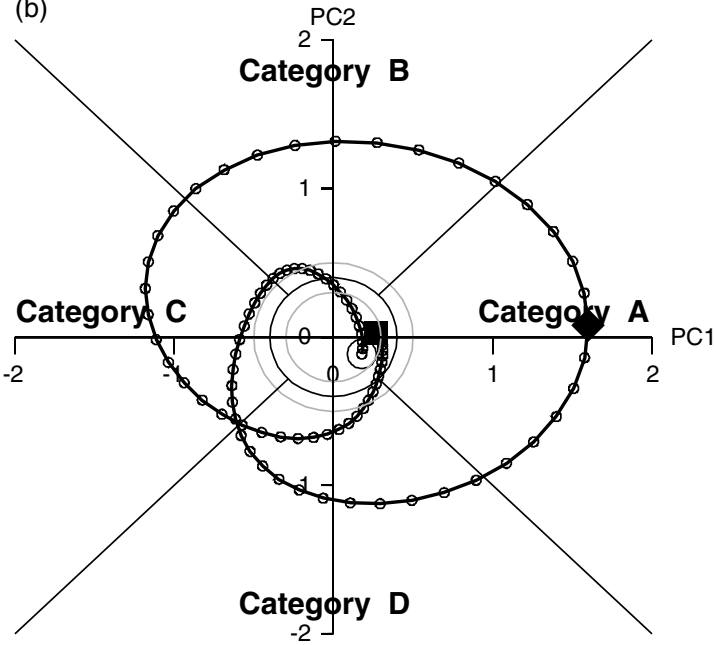

(c)

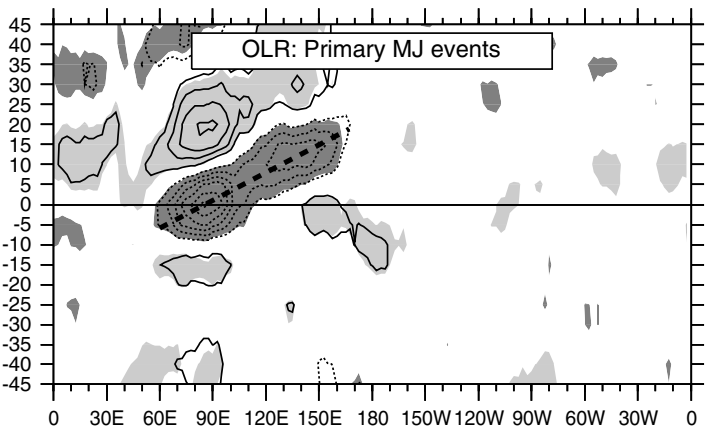

(d)

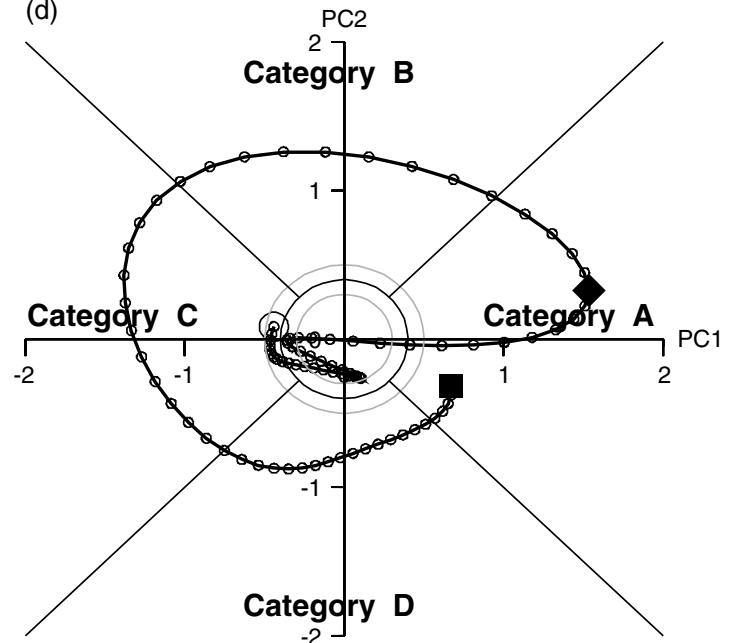

Figure 3. (a) Composite Hovmöller diagram of 20-200-day filtered OLR anomalies averaged from $10^{\circ} \mathrm{S}$ to $10^{\circ} \mathrm{N}$, for successive $\mathrm{MJ}$ events (DABCD). The contour interval is $2.5 \mathrm{~W} \mathrm{~m}^{-2}$, negative contours are dotted and the zero contour is omitted. Regions statistically significant at the 5\% level are shaded. The bold lines show the approximate central propagation path of the main OLR anomalies. (b) Corresponding (PC1,PC2) phase-space diagram. The first $(t=-45)$, central $(t=0)$ and last $(t=45)$ days are shown by an open circle, a filled diamond, and a filled square, respectively. See text for details. (c) and (d) are as (a) and (b), but for primary MJ events (NABCD). The contour interval in (c) is $5 \mathrm{~W} \mathrm{~m}^{-2}$. 


\subsection{Primary MJ events}

Primary MJ events beginning over the Indian Ocean are defined by the string 'NABCD', i.e. a period of no MJO activity ' $N$ ', followed by a full cycle 'ABCD'. An example of a primary MJ event is shown in Figure 2(c,d). The start time $(t=0)$ when PC1 was a maximum was 28 September 1992 (horizontal line in Figure 2(c)). Enhanced precipitation (negative OLR anomalies) were present over the Indian Ocean at $80^{\circ} \mathrm{E}$ at this time. Eastward propagation of this anomaly and then the subsequent development and eastward propagation of positive OLR anomalies during October 1992 can also be seen. On 13 September 1992, 15 days prior to the convective peak over the Indian Ocean, there is a positive OLR anomaly at the same longitude, indicating suppressed convection. Neither this, nor any of the other anomalies prior to the MJ event, show any coherent eastward (or westward) propagation. Hence, there is no previous MJO cycle before this primary MJ event. The phase-space diagram for this primary MJ event (Figure 2(d)) shows no coherent behaviour before $t=0$ (indicated by the filled diamond), but once the MJ event is established at $t=0$ there is a clear anticlockwise trajectory around the origin.

The composite Hovmöller diagram of tropical OLR anomalies (Figure 3(c)), averaged over the total of 26 primary MJ events (Table I; the 'NABCD' event that followed the missing data in 1978 was not included) confirms the robustness and statistical significance (from a t-test) of the suppressed, stationary convective anomaly over the Indian Ocean at $t=-15$ days. Note that there is also a positive OLR anomaly at $80^{\circ} \mathrm{E}$ at $t=-15$ during the successive MJ events (Figure 3(a)), but this is part of a larger eastward propagating anomaly and cannot be unambiguously ascribed to either the current or previous MJ event. In the primary MJ event, this anomaly can be unambiguously attributed to the current event. About 7 days later, the enhanced convection of the primary MJ event begins, and then propagates eastward. The phasespace diagram of the composite events (Figure 3(d)) shows no coherent behaviour at negative lags (random motion near the origin, within the circle of the ' $N$ ' category), confirming the lack of coherent eastward propagation before the start of a primary MJ event.

Note also that the contour interval for composite primary MJ events (Figure 3(c)) is double that for the composite successive MJ events (Figure 3(a)). This is because of the smaller sample size, and subsequently noisier composite maps, for the primary events. The actual amplitudes of anomalies are quite similar between primary and successive events.

Calculations with unfiltered data produced similar results to those with the 20-200-day filtered data. Also, the seasonal distributions of the primary and successive MJ events are similar, with more events in northern winter than summer. The mean total time of an event, i.e. an 'ABCD' cycle, is 44.8 and 42.1 days, for primary and successive events, respectively. These are statistically indistinguishable. Hence, any differences between primary and successive MJ events are 'real', in the sense that they are not an artifact of the filtering, or due to a seasonal bias, or differences in MJO period.

\subsection{Starting location of MJ events}

The assumption that MJ events start with active convection in the Indian Ocean (category A) is tested by counting the numbers of primary MJ events. There were 26 such primary events (instances of 'NABCD' in Table I). Alternative primary $\mathrm{MJ}$ events can be defined that start with active convection over Indonesia ('NBCDA'; 12 events), over the western Pacific ('NCDAB'; 13 events) and over Africa and the western Indian Ocean ('NDABC'; 12 events), giving a total of 63 distinct, nonoverlapping primary MJ events. These are summarised in Table II. Hence, although the Indian Ocean was the most frequent starting location for the primary MJ events, these accounted for only $40 \%$ of the total.

Similarly, the arbitrary 'starting location' of successive MJ events can also be examined. There were 82, 89, 81 and 82 events starting at each of the four locations, respectively (Table II). These numbers are statistically indistinguishable, hence there is no preferred 'starting location' for successive MJ events. Note that most of these successive MJ events will overlap; there are not 334 mutually exclusive MJ events here.

For completeness, the other possible types of MJ events are also counted. The 'initial westward' events involve a reversal of the usual eastward propagation, or anticlockwise propagation in (PC1,PC2) phase space. For example, there are 8 'BABCD' events, where enhanced convection over Indonesia ('B') then moved westward to the Indian Ocean ('A') before reversing and completing a conventional MJO cycle. There were also a nonnegligible number of these types of events starting at

Table II. Number of instances of MJ events.

\begin{tabular}{lccccr}
\hline $\begin{array}{l}\text { Start location } \\
\text { MJ event }\end{array}$ & $\begin{array}{c}\text { Indian Ocean } \\
\text { ABCD }\end{array}$ & $\begin{array}{c}\text { Indonesia } \\
\text { BCDA }\end{array}$ & $\begin{array}{c}\text { Western Pacific } \\
\text { CDAB }\end{array}$ & $\begin{array}{c}\text { Africa } \\
\text { DABC }\end{array}$ & Total \\
\hline Primary & NABCD 26 & NBCDA 12 & NCDAB 13 & NDABC 12 & 63 \\
Successive & DABCD 82 & ABCDA 89 & BCDAB 81 & CDABC 82 & $\geq 89$ \\
Initial westward & BABCD 8 & CBCDA 11 & DCDAB 4 & ADABC 9 & 32 \\
Initial opposite & CABCD 0 & DBCDA 0 & ACDAB 0 & BDABC 0 & 0 \\
Total & 116 & 112 & 98 & 103 & \\
\hline
\end{tabular}


the other locations; 11 'CBCDA' events starting over Indonesia, 4 'DCDAB' events starting over the western Pacific, and 9 'ADABC' events starting over Africa.

The other possible type of event, termed an 'initial opposite' event, where an MJ event is preceded by the opposite category to its initial category, e.g. 'CABCD', does not occur in practice, as the state of the MJO would have to flip from one category to its opposite category in one day, without passing through any other categories.

In summary, MJ events can start at any location, and the common assumption that they begin over the Indian Ocean should be treated with caution. However, of the 63 primary events, whose starting locations can be unambiguously determined, $40 \%$ of them do begin over the Indian Ocean. Furthermore, if the 63 primary events and 32 initial westward events are grouped together, there are $95 \mathrm{MJ}$ events with no previous coherent eastward propagation. This compares to a similar number (at least 89) of distinct successive events, where previous eastward propagation was present. Hence, the periodic view of the MJO accounts for about half of the events, and the discrete view accounts for the other half.

\section{Precursor signals for the MJO}

The categorisation method of section 3 has succeeded in isolating primary MJ events. Composites of the primary events that start over the Indian Ocean show no eastward propagation of convective anomalies before the start of the event (negative lags in Figure 3(c)). However, there is a stationary suppressed convective anomaly that grows and decays immediately before the start of primary MJ events in the Indian Ocean. This is investigated further in this section, and precursor signals in other variables are sought. In particular, differences in behaviour between the successive and primary MJ events are investigated. Only events starting in the Indian Ocean are considered, as the sample sizes for primary events starting elsewhere were too small to produce robust statistical conclusions.

\subsection{Convective anomalies}

Lagged composite maps of OLR anomalies for the successive MJ events show the familiar cyclical eastward propagation. On day -25 (Figure 4(a)), there is a 'reversed dipole' pattern with suppressed convection over Africa and the Indian Ocean, and enhanced convection over the western Pacific. These anomalies propagate slowly eastward, such that there is suppressed convection over Indonesia on day -15 (Figure 4(b)), the dipole pattern of enhanced convection over Africa and the Indian Ocean, and suppressed convection over the western Pacific on day -5 (Figure 4(c)), enhanced convection over Indonesia on day 5 (Figure 4(d)), then back to the reverse dipole pattern on day 15 (Figure 4(e)). The MJO described by these composites of the successive events is essentially that described in many previous observational studies. It is cyclical with a period of approximately
40 days. As such, it is not possible to define a meaningful start or end to the MJO, and any particular feature cannot be ascribed to either the 'current' or 'previous' event.

By design, the lagged composite maps for the primary MJ events do indicate a clear start to the events. On day -5 (Figure $4(\mathrm{~h})$ ), there is enhanced convection building over the Indian Ocean, but no convective anomalies to the west over Africa. The primary MJ events at this and later stages (Figure $4(\mathrm{i}, \mathrm{j})$ ) are similar to the successive events. However, on day -15 (Figure $4(\mathrm{~g})$ ) there are positive OLR anomalies over the equatorial Indian Ocean, indicating suppressed convection there. These anomalies are absent on day -25 (Figure 4(f)), and appear in situ without any eastward propagation. Hence they are not part of a previous MJO cycle.

These anomalies are locally significant on the gridpoint scale at the $5 \%$ level by a t-test (shading in Figure $4(\mathrm{~g}))$. However, extra care must be taken as, by definition, $5 \%$ of (area-weighted) grid points would be expected to be locally significant, by chance, even if there was no 'true' signal. Over the warm pool domain of interest (a rectangular box between $50^{\circ} \mathrm{E}$ and $180^{\circ} \mathrm{E}$, and $15^{\circ} \mathrm{S}$ and $\left.15^{\circ} \mathrm{N}\right), 13.8 \%$ of the area-weighted grid points passed the local significance test at the $5 \%$ level in Figure $4(\mathrm{~g})$. This is clearly much higher than the expected $5 \%$ if there was no signal. However, large areas of locally significant anomalies can still arise by chance because of the spatial correlations in the data. Hence, a further test for the field or global significance of the entire pattern was carried out (e.g. Barnston and Livezey, 1987). A random composite was generated by taking the original list of 26 ' $t=-5$ ' dates that formed the original composite, and changing those dates randomly. As the MJO varies seasonally, the seasonal distribution of the original dates was preserved. For each randomised date, the year was allowed to take on any random value within the 31-year dataset, but the day of the year was only allowed to change randomly by up to \pm 15 days. Hence, the randomised date was at approximately the same part of the annual cycle as the original date. A composite anomaly map was then calculated based on these 26 randomised dates. 500 such random composites were calculated. The percentage of area-weighted grid points that passed the local significance test at the 5\% level in each random composite was calculated. A frequency distribution of these 500 values was then compiled. The 95th percentile of this distribution was $10.7 \%$. Hence, even if there was no signal, in $5 \%$ of random composites the percentage of area-weighted grid points that was locally significant at the 5\% level would exceed $10.7 \%$, purely by chance. As this value was exceeded by the observed value of $13.8 \%$, then the entire pattern in Figure $4(\mathrm{~g})$ has field significance at the $5 \%$ level.

\subsection{Thermodynamical forcing}

The precursor suppressed convective anomaly over the Indian Ocean is a robust feature of primary MJ events. We can state at a confidence level of $5 \%$ that it has 
(a)

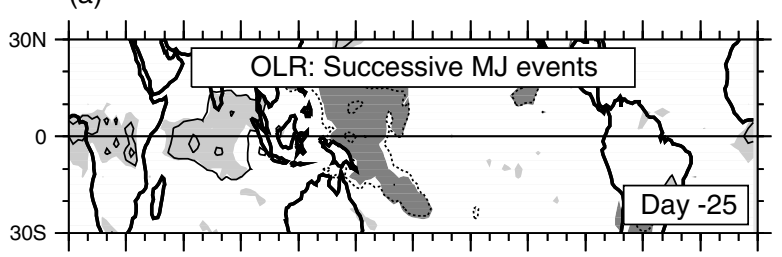

(b)

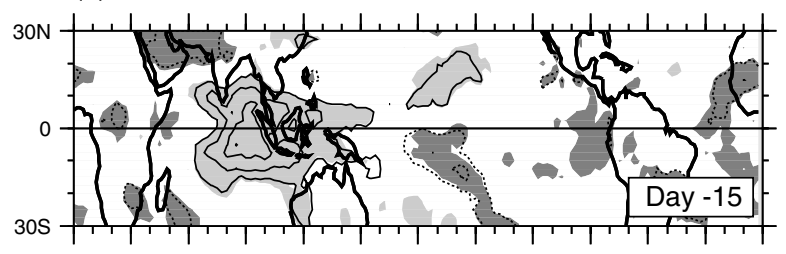

(c)

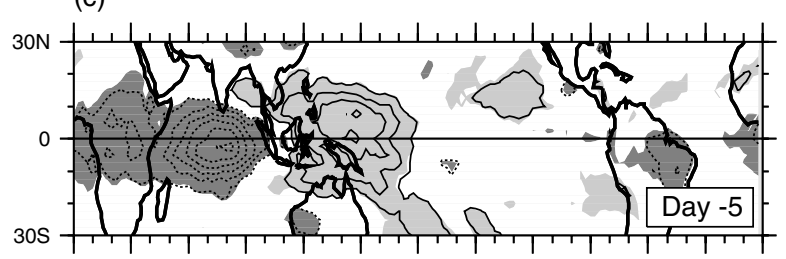

(d)

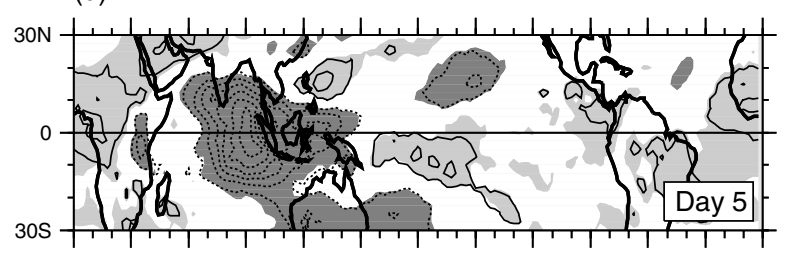

(e)

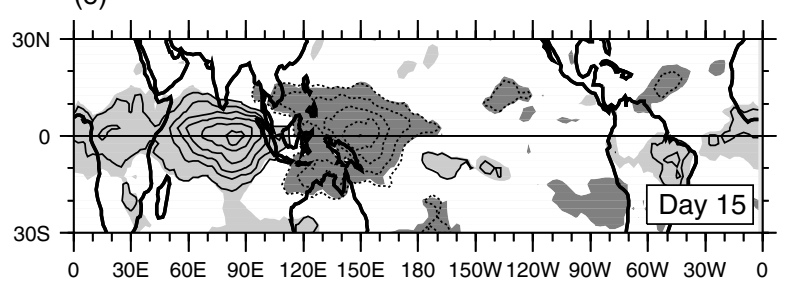

(f)

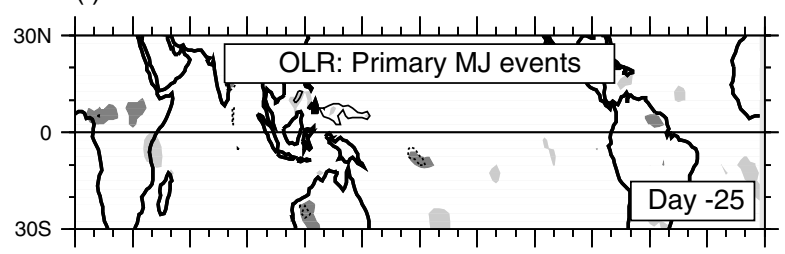

(g)

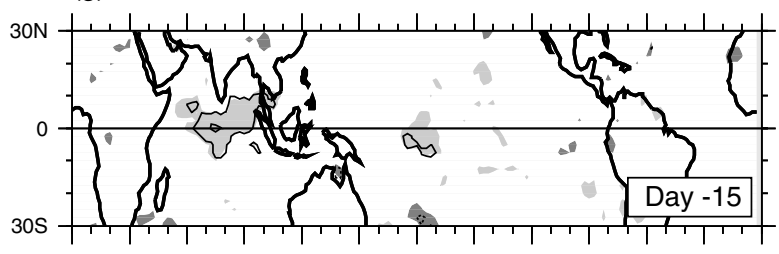

(h)

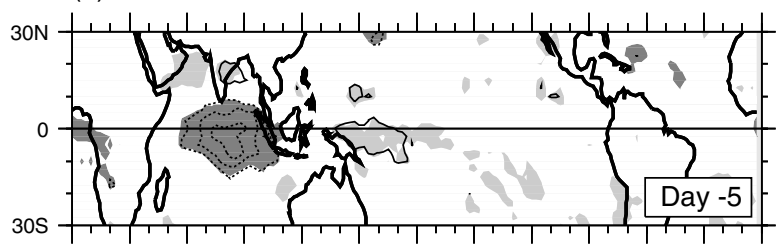

(i)

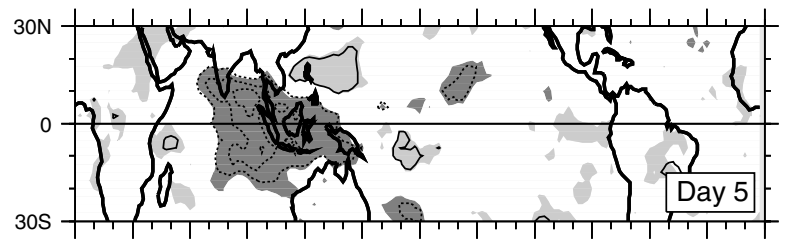

(j)

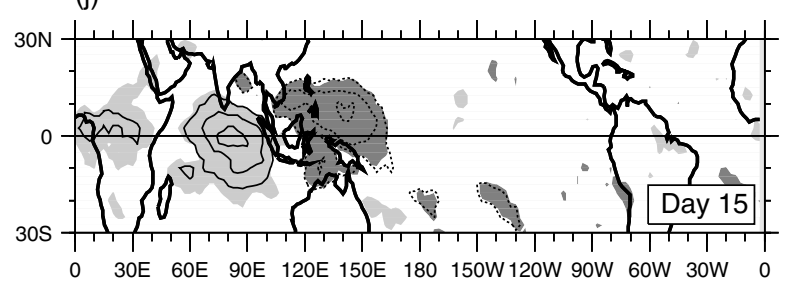

Figure 4. Composite maps of OLR anomalies for successive MJ events at (a) day -25 , (b) day -15 , (c) day -5 , (d) day 5 , (e) day 15 , and for primary MJ events at (f) day -25 , (g) day -15 , (h) day -5 , (i) day 5 , (j) day 15 . The contour interval is $4 \mathrm{~W} \mathrm{~m}^{-2}$ in (a) $-(\mathrm{d})$, and $8 \mathrm{~W} \mathrm{~m} \mathrm{~m}^{-2}$ in (e)-(h). Negative contours are dotted, and the zero contour is omitted. Local statistical significance at the 5\% level is shown by grey shading.

not arisen by chance. Such a feature may influence the subsequent initiation of the MJ event by several mechanisms. First, the impact on the thermodynamical structure of the atmosphere is investigated. Changes in tropical convection have associated changes in latent heat release in the middle troposphere. These lead to changes in temperature which generate equatorial Kelvin and Rossby waves that propagate the signal eastwards and westwards, respectively.

For the successive events, a mechanism by which the MJO may be regenerated is by the eastward propagation of a Kelvin wave from the previous MJ event right around the Equator to trigger the next event. Such eastward circum-equatorial propagation has been observed in upper- and lower-tropospheric winds and divergence, mid-tropospheric temperatures (Knutson and Weickmann, 1987; Hendon and Salby, 1994; Bantzer and Wallace, 1996) and sea-level pressure (Matthews, 2000). The arrival of eastward-propagating cold mid-tropospheric temperature anomalies over West Africa, forced by the $\mathrm{MJO}$, can destabilise the atmosphere and trigger intraseasonal convective anomalies over the West African monsoon (Matthews, 2004a).

The mid-tropospheric MSU3/4 composite anomalies during the successive MJ events partially support this scenario (Figure 5(a)). The suppressed convective phase in the previous MJ event (schematic solid line in Figure 5(a)) forces an upwelling equatorial Kelvin wave, with ascending motion at the wave front and cold midtropospheric temperature anomalies behind, that propagates rapidly eastward at day -10 . This reaches the Indian Ocean sector from the west at day -5 at the same time as the enhanced convection in the current MJ event peaks there. The characteristic equatorially trapped horizontal structure of the equatorial Kelvin wave, with a maximum on the Equator, can be 
(a)

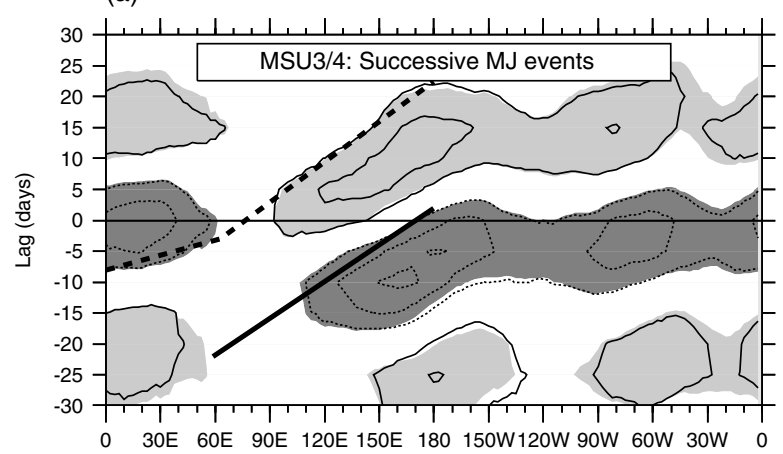

(b)

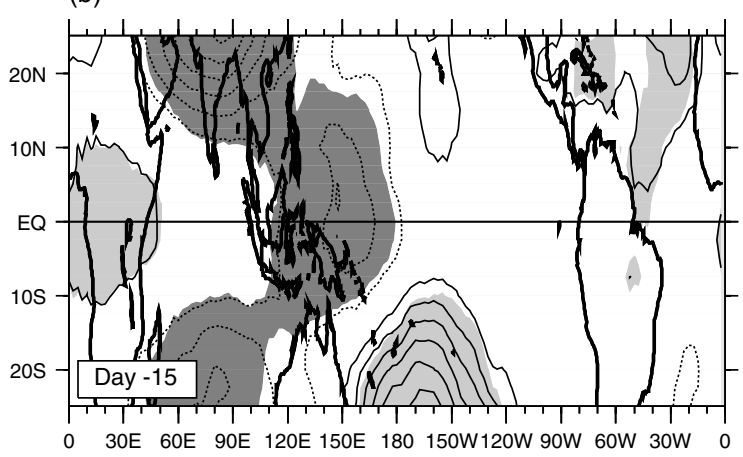

(c)

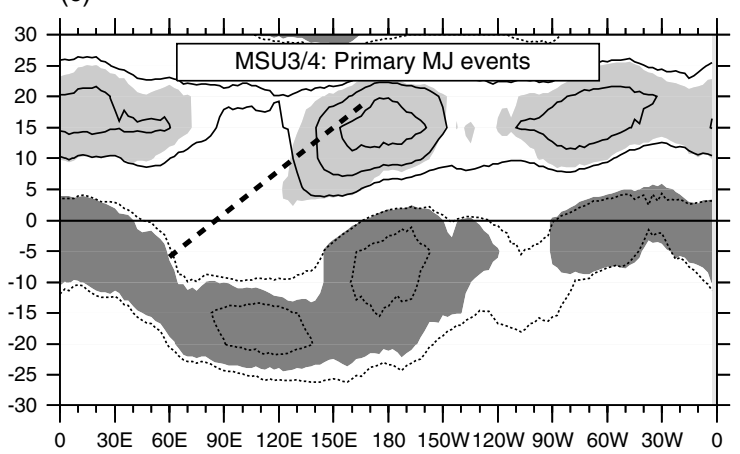

(d)

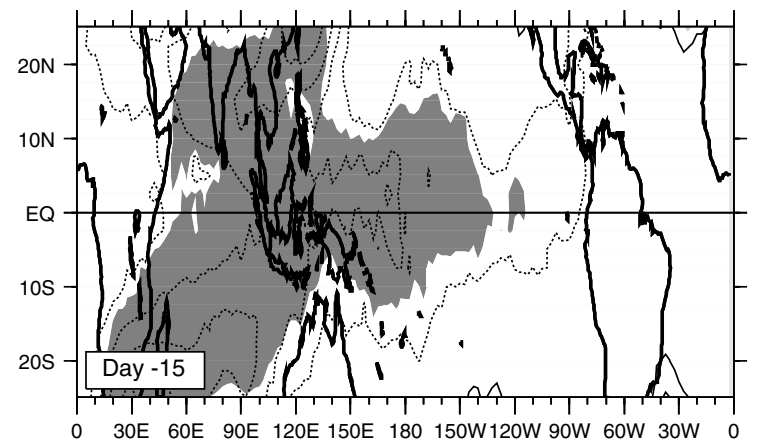

Figure 5. Composites of 20-200-day filtered MSU3/4 temperature anomalies for successive MJ events (DABCD). (a) Hovmöller diagram, averaged from $10^{\circ} \mathrm{S}$ to $10^{\circ} \mathrm{N}$. The thick lines show the approximate central propagation path of the negative OLR anomalies from Figure 3 . (b) Anomaly map at day -15 . The contour interval is $0.1 \mathrm{~K}$, negative contours are dotted and the zero contour is omitted. Regions statistically significant at the $5 \%$ level are shaded. (c) and (d) are as (a) and (b), but for primary MJ events (NABCD).

seen in Figure 5(b). Hence, although these destabilising temperature anomalies seem to arrive too late to actually trigger the start of the next round of convection, they would act to enhance it. Once the enhanced convection is established at day 5, it forces a downwelling Kelvin wave with descent at the wave front, and warm midtropospheric temperature anomalies behind, that propagates eastward around the Equator and arrives over the Indian Ocean at day 10 , in time to help maintain the dry phase of the MJO there.

The negative convective anomaly over the Indian Ocean at day -15 in the primary events also forces a downwelling equatorial Kelvin wave. Negative temperature anomalies propagate rapidly eastward from the Indian Ocean across the Pacific to the Atlantic by day 0 (Figure 5(c)). The propagation across the Pacific can be seen in the snapshot at day -15 (Figure $5(\mathrm{~d})$ ), where the characteristic Kelvin wave structure with maximum amplitude on the Equator can clearly be seen. However, of more relevance here is the westward propagation of negative temperature anomalies from the eastern Indian Ocean at day -15 to the western Indian Ocean by day -5 (Figure 5(c)). This negative mid-tropospheric temperature anomaly would destabilise the atmosphere to deep convection. Immediately after it arrives there, the enhanced deep convection of the primary MJ event begins. Under the classical Gill (1980) model, westward propagation is associated with an equatorial Rossby wave structure, as shown by the off-equatorial temperature minima over the Indian Ocean on day -15 (Figure 5(d)).

A vertical section of equatorial NCEP-NCAR reanalysis temperature anomalies on day -15 of the successive MJ events (Figure 6(a)) confirms that the negative temperature anomalies over the warm pool peak in the mid-troposphere near $300 \mathrm{hPa}$. There are positive temperature anomalies above, sloping upward towards the east, consistent with the analysis of Kiladis et al. (2005), and indicating eastward and upward propagation of a Kelvin wave. These features are broadly reproduced in the primary MJ events (Figure 6(b)). Hence, this feature of the MJO can be unambiguously attributed to the current MJ event, and is not dependent on a previous event.

Therefore, the negative mid-tropospheric temperature anomaly over the Indian Ocean at day -15 and its subsequent westward propagation by an equatorial Rossby wave will lead to destabilisation of the atmosphere to convection, consistent with the start of the primary MJ event.

\subsection{Boundary-layer convergence and moisture}

Boundary-layer moisture plays a crucial role in some MJO theories. In particular, the frictional moisture convergence theory first put forward by Wang (1988) assumes there is a feedback between the frictionally induced (moisture) convergence in the Ekman boundary layer ahead (to the east) of the Kelvin wave response to the active MJO convection, which then destabilises the 
(a)

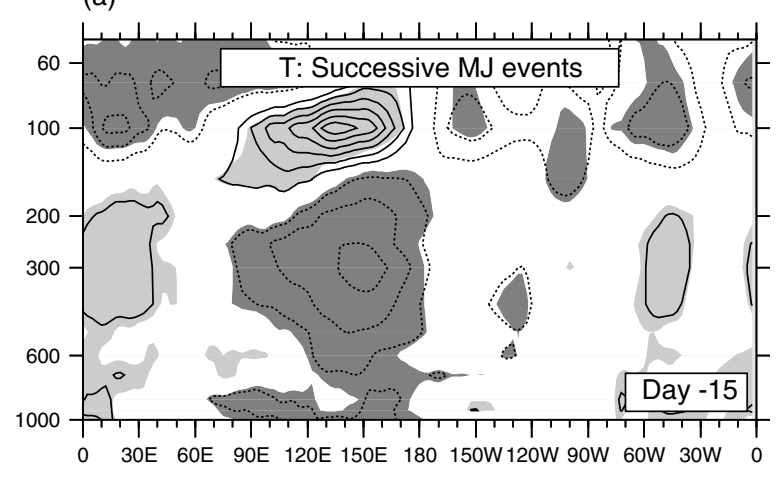

(b)

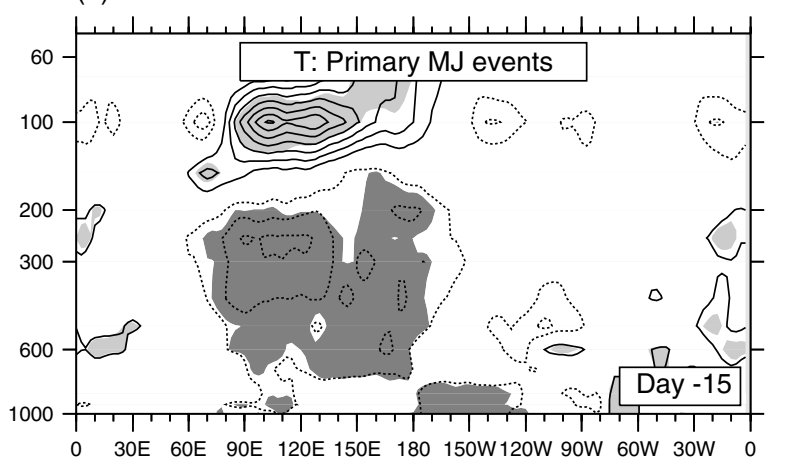

Figure 6. Longitude-pressure section of NCEP temperature anomalies along the Equator (averaged $10^{\circ} \mathrm{S}-10^{\circ} \mathrm{N}$ ) at day -15 for (a) successive and (b) primary MJ events. The contour interval is $0.1^{\circ} \mathrm{C}$, negative contours are dotted and the zero contour is omitted. Regions statistically significant at the $5 \%$ level are shaded.

atmosphere and causes the convection to move further east. The frictional moisture convergence part of this theory has been observed, with positive humidity and negative divergence boundary-layer anomalies to the east of the active MJO convection (Hendon and Salby, 1994; Maloney and Hartmann, 1998; Kiladis et al., 2005). Conversely, the observed frictional (moisture) divergence in the Rossby wave response to the west of the active MJO convection has been hypothesised to lead to the suppression of convection there, and the establishment of the convective dipole pattern (Matthews, 2000).

These features can be seen in the composite 1000$\mathrm{hPa}$ divergence anomalies for the successive MJ events (Figure 7(a)). Negative (convergence) anomalies lead the active convection (shown schematically by the bold dotted line) over the entire warm pool sector. On day -10 , these convergence anomalies can be seen over the Indian Ocean, mainly to the east of the active convection over the western Indian Ocean at this time, and preceding the peak convection over the Indian Ocean 10 days later.

However, there are no precursor convergence anomalies before the primary MJ events start (negative lags in Figure 7(b)). Once the primary MJ events do start, a boundary-layer convergence anomaly rapidly develops at $90^{\circ} \mathrm{E}$. However, the phasing is different. The convergence anomaly peaks after the convection (at $90^{\circ} \mathrm{E}$, day 3 in Figure 7(b)) in the primary MJ events, rather than before the convection as it does in the successive MJ events (at $80^{\circ} \mathrm{E}$, day -5 in Figure 7(a)). However, once the primary MJ event is fully established, the familiar divergence-convection phasing reappears, with a rapid Kelvin wave response and convergence anomalies to the east of the convection.

The boundary-layer specific humidity anomalies follow similar patterns as the boundary-layer divergence. Negative (positive) humidity anomalies lead the suppressed (active) convection throughout the successive MJ events (Figure 8(a)). For example, on day -10 during the successive MJ events, the atmosphere is premoistened (positive humidity anomaly) over the western Indian Ocean from the surface $(1000 \mathrm{hPa})$ up to the midtroposphere (400 hPa; Figure 9(a)), consistent with the radiosonde analyses of Kemball-Cooke and Weare (2001) and Kiladis et al. (2005), and the discharge-recharge mechanism of Bladé and Hartmann (1993). As the successive MJ event develops, positive boundary-layer humidity anomalies develop to the east of the active convection, particularly over the Pacific sector. These are associated with the increased evaporation due to the enhanced surface easterlies as part of the Kelvin wave (a)

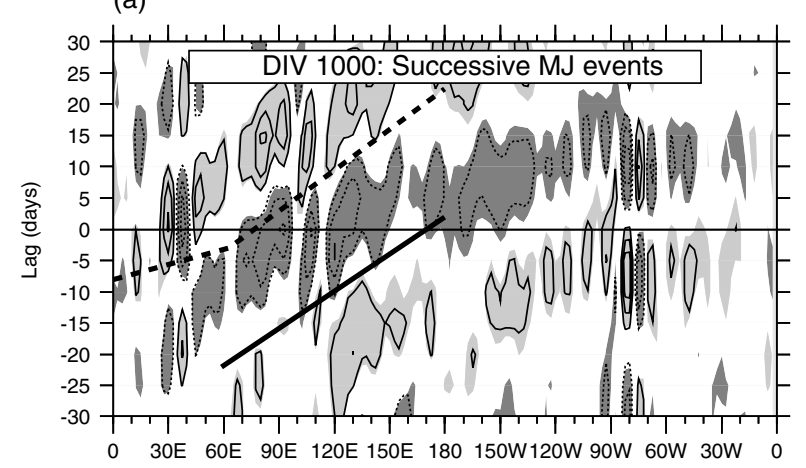

(b)

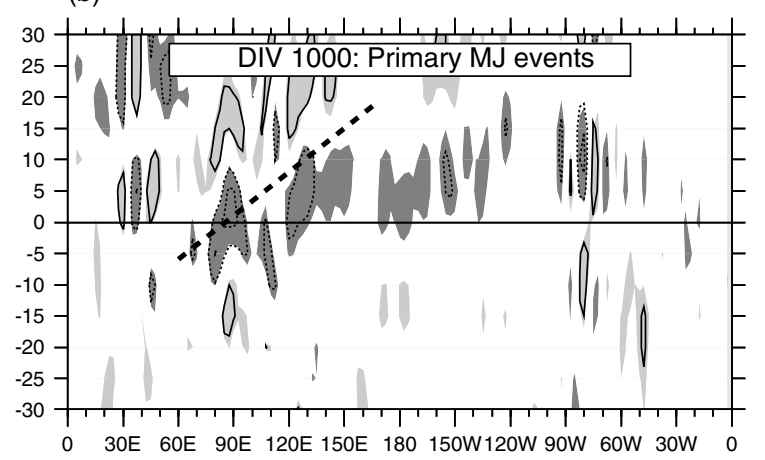

Figure 7. Hovmöller diagrams of 20-200-day filtered $1000 \mathrm{hPa}$ divergence anomalies, averaged from $10^{\circ} \mathrm{S}$ to $10^{\circ} \mathrm{N}$, for (a) successive MJ events (DABCD), with contour interval $2 \times 10^{-7} \mathrm{~s}^{-1}$, and (b) primary MJ events (NABCD), with contour interval $4 \times 10^{-7} \mathrm{~s}^{-1}$. Negative contours are dotted and the zero contour is omitted. Regions statistically significant at the 5\% level are shaded. The bold lines show the approximate central propagation path of the main OLR anomalies from Figure 3. 
(a)

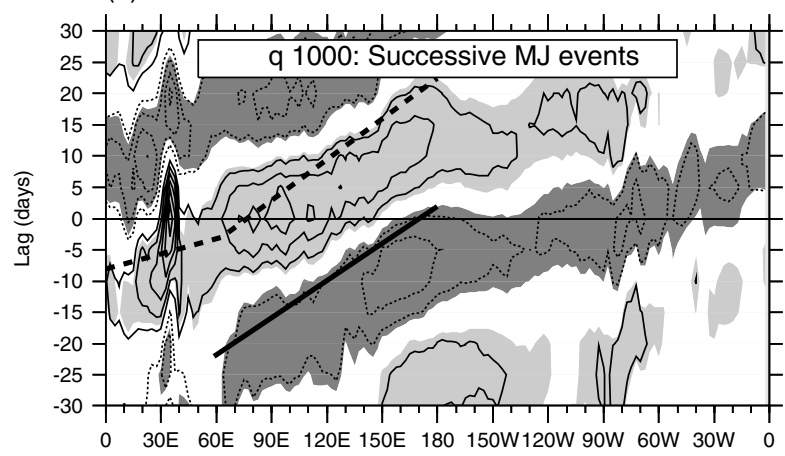

(b)

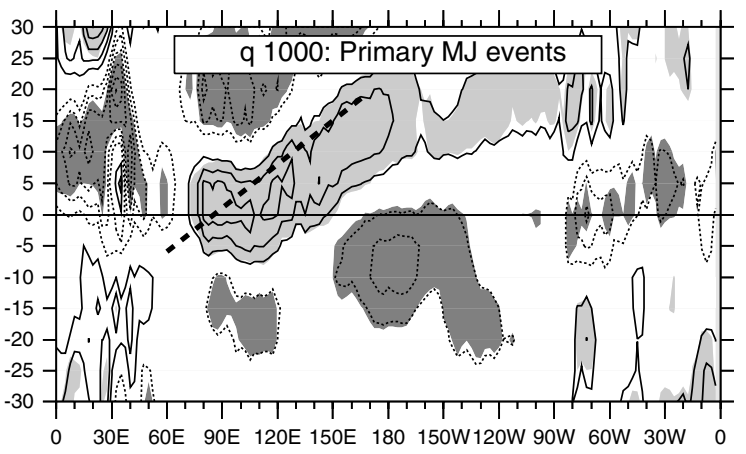

Figure 8. As Figure 7, but for $1000 \mathrm{hPa}$ specific humidity anomalies. The contour interval is $0.1 \mathrm{~g} \mathrm{~kg}^{-1}$.

(a)

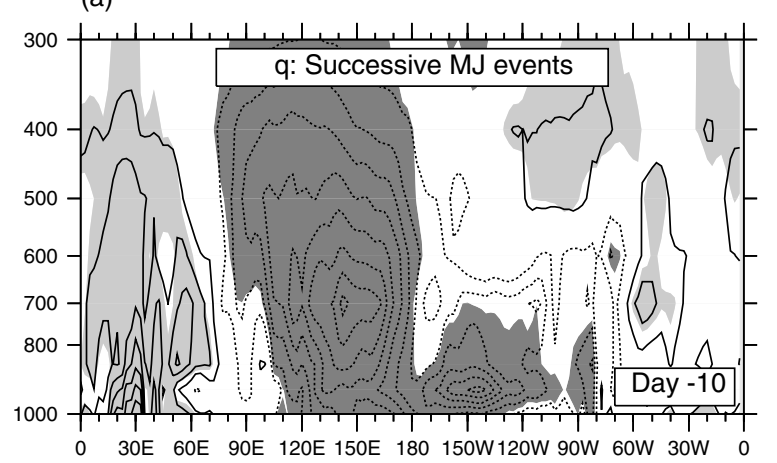

(b)

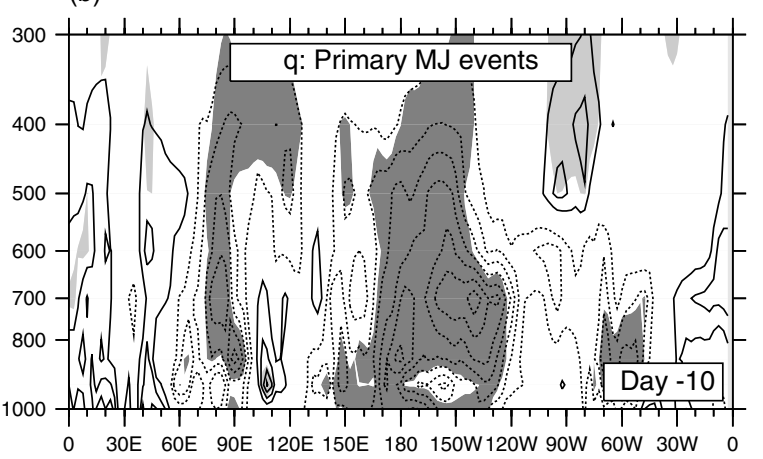

Figure 9. Longitude-pressure section of specific humidity anomalies along the Equator (averaged $10^{\circ} \mathrm{S}-10^{\circ} \mathrm{N}$ ) at day -10 for (a) successive and (b) primary MJ events. The contour interval is $0.05 \mathrm{~g} \mathrm{~kg}^{-1}$, negative contours are dotted and the zero contour is omitted. Regions statistically significant at the $5 \%$ level are shaded.

response to the enhanced MJO convection (Kiladis et al., 2005).

During the primary $\mathrm{MJ}$ events, there is a dry anomaly associated with the precursor suppressed convection over the Indian Ocean that extends from the surface up to the mid-troposphere (Figures 8(b), 9(b)). Also, once the enhanced convection is established (thick dotted line in Figure 8(b)), a moist anomaly is set up to the east (Figure 8(b)), presumably by the Kelvin wave-evaporation mechanism, and positive humidity anomalies again lead the active MJ convection. However, at the initiation of the primary MJ event, there is no corresponding pre-moistening of the atmosphere, shown by the lack of any significant positive humidity anomalies over the Indian Ocean in Figures 8(b) and 9(b).

Hence, it appears that the frictional moisture convergence and pre-moistening mechanisms may be important for the maintenance and eastward propagation of established MJ events, but do not have an influence on the spontaneous generation of the MJO.

\subsection{Forcing by the ocean}

The importance of air-sea interactions within the MJO has been emphasised recently (Hendon, 2005). Positive SST anomalies are observed to lead enhanced MJO convection by a quarter cycle, with the changes to
SST being due to surface latent heat and short-wave radiation flux anomalies (Flatau et al., 1997; Shinoda et al., 1998; Woolnough et al., 2000). MJO convection anomalies in atmospheric models have been simulated as a forced response to idealised intraseasonal SST anomalies (Woolnough et al., 2001) and observed SST anomalies (Matthews, 2004b). Coupling of atmosphere and ocean models has generally lead to improved and more coherent simulations of the MJO (Sperber et al., 1997; Waliser et al., 1999; Inness and Slingo, 2003), provided that the basic climatology of the model was sufficiently accurate (Hendon, 2000). Hence, SST perturbations are a possible candidate for an external trigger for primary $\mathrm{MJ}$ events.

The composite SST anomalies in the successive MJ events follow a similar pattern to those previously described, with positive SST anomalies leading the enhanced convection over the Indian Ocean and Indonesia by approximately a quarter cycle (Figure 10(a)), with positive SST anomalies covering almost the entire equatorial Indian Ocean on day -15 (Figure 10(b)). This pattern has field significance at the $1 \%$ level.

However, there are no coherent SST anomalies preceding the primary MJ events (Figure 10(c,d)). Although there are small scattered areas of locally significant positive SST anomalies over the Indian Ocean on day -15 (Figure 10(d)), these do not pass a field significance test 
(a)

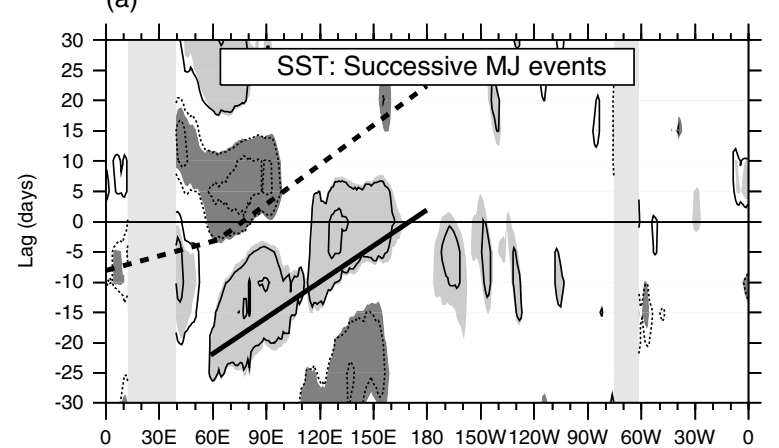

(b)

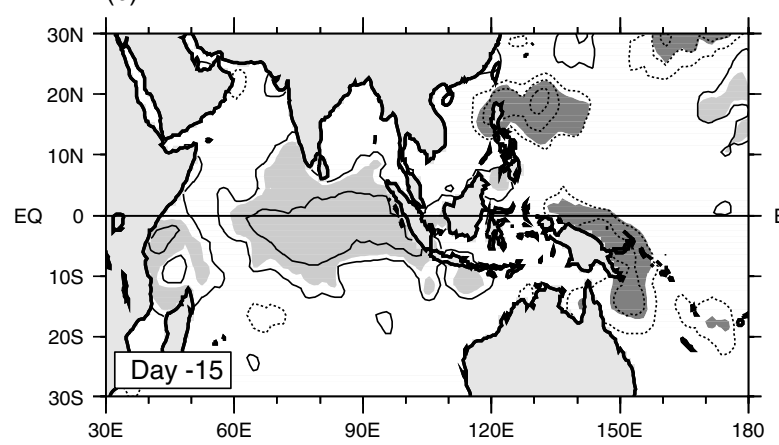

(c)

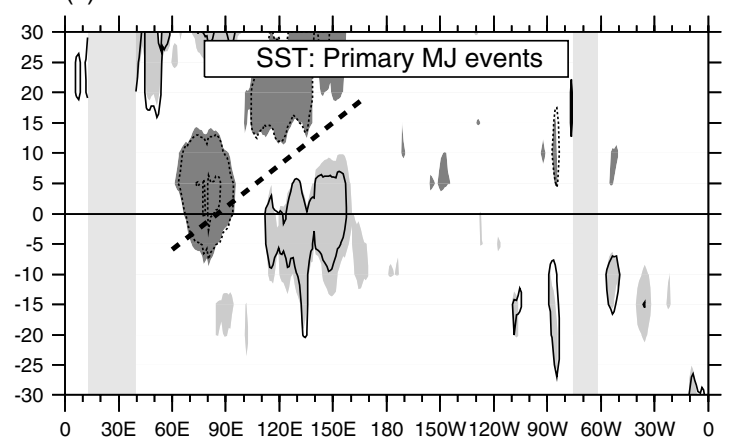

(d)

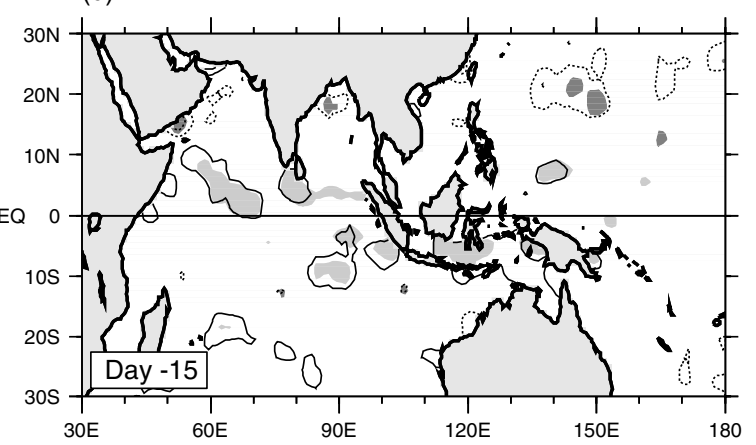

Figure 10. Composites of 20-200-day filtered sea surface temperature anomalies for successive MJ events (DABCD). (a) Hovmöller diagram, averaged from $10^{\circ} \mathrm{S}$ to $10^{\circ} \mathrm{N}$. The bold lines show the approximate central propagation path of the main OLR anomalies from Figure 3 . (b) Anomaly map at day -15 . The contour interval is $0.05 \mathrm{~K}$, negative contours are dotted and the zero contour is omitted. Regions statistically significant at the $5 \%$ level are shaded. (c) and (d) are as (a) and (b), but for primary MJ events (NABCD), and the contour interval is 0.1 K.

at even the $10 \%$ level, and hence could have arisen by chance.

Once the primary MJ events are established, the SST anomalies appear as in the canonical successive MJ events. Hence, SST perturbations, random or otherwise, do not seem to be able to spontaneously generate MJ events, and air-sea interaction only appears to be important once the MJO is established.

\subsection{Forcing by synoptic wave activity}

Another possible mechanism for dynamical forcing of the MJO is by equatorward-propagating transient waves in the Northern Hemisphere. Hsu et al. (1990) observed that convection over the Indian Ocean during an MJO in the 1985-1986 northern winter was triggered by the arrival of a higher-frequency subtropical Rossby wave train that propagated southwards from the African-Asian jet. A similar forcing of MJO convection by such highfrequency Rossby waves has also been observed over the central Pacific (Matthews and Kiladis, 1999). Eastward propagating low-frequency tropical wave disturbances have also been forced by extratropical synoptic eddies in model experiments (Hoskins and Yang, 2000; Lin et al., 2007).

A useful diagnostic of this transient Rossby wave activity is the kinetic energy of the high-frequency (20day high-pass filtered) wind anomalies at $200 \mathrm{hPa}$. Prior to the start of the successive MJ events, a band of enhanced high-frequency kinetic energy between 10 and $30^{\circ} \mathrm{N}$ is observed to lead the MJO convection over the African and Indian Ocean sectors (Figure 11(a)). On day -10 , this area of enhanced wave activity extends from the African-Asian jet region at $25^{\circ} \mathrm{N}$ southwards deep into the tropics to $10^{\circ} \mathrm{N}$ (Figure 11(b)). This is consistent with the hypothesis that subtropical Rossby wave activity organises MJO convection. There are also large kinetic energy anomalies over the Pacific sector, but these do not coincide with enhanced MJO convection, possibly because this analysis is not confined to the northern winter.

However, there are no coherent high-frequency kinetic energy anomalies during the primary MJ events (Figure 11(c,d)). Hence, it appears that the enhancement of Rossby wave activity prior to the successive MJ events is due to the previous MJ event. This could be due to an enhanced high-frequency Rossby wave source from within the MJO or to the preferential refraction of ambient Rossby waves into the Indian Ocean region by the slowly varying MJO upper-tropospheric wind field (Matthews and Kiladis, 2000). Again, this mechanism may help to generate the next MJ event from an existing one, but does not appear to be important in generating new MJ events in the absence of a pre-existing event.

\section{Conclusions}

Due to the quasi-cyclical nature of the MJO, conventional analyses give a cyclical view where one cycle merges into the next, the start location of the cycle is arbitrary, and 
(a)

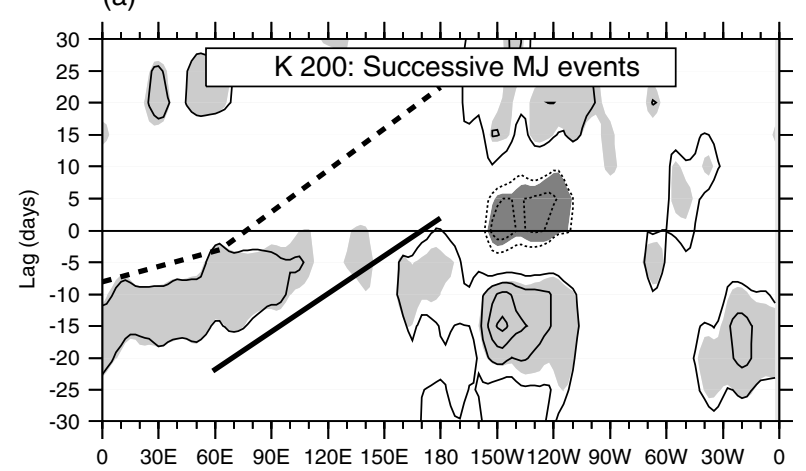

(b)

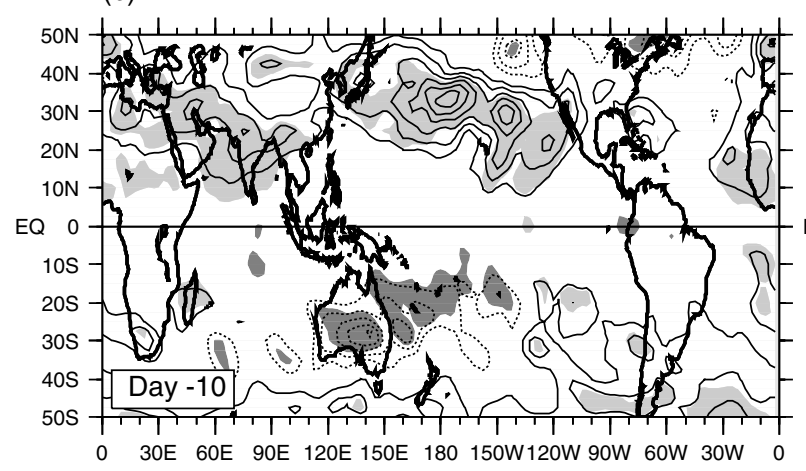

(c)

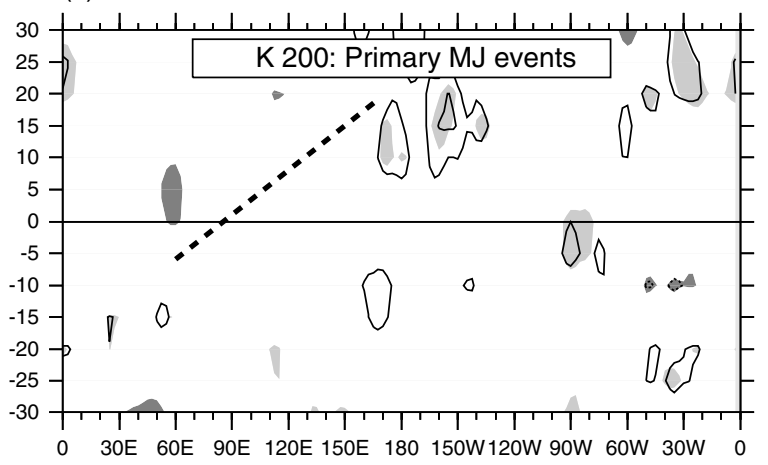

(d)

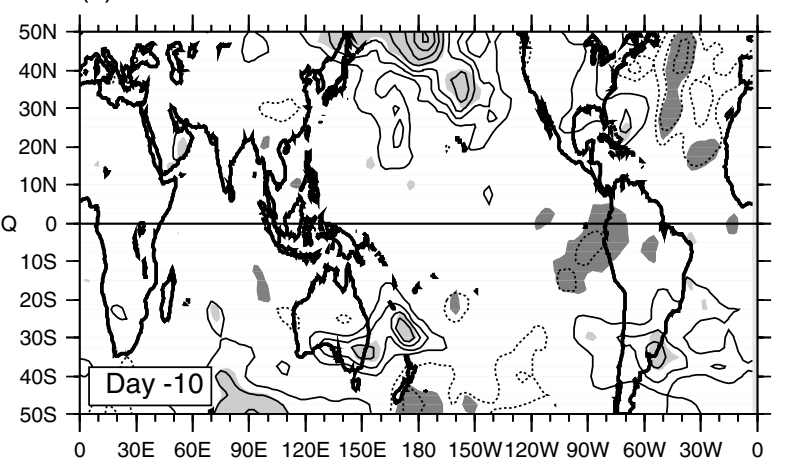

Figure 11. Composites of 20-day high-pass filtered kinetic energy anomalies for successive MJ events (DABCD). (a) Hovmöller diagram, averaged from $10-30^{\circ} \mathrm{N}$. The bold lines show the approximate central propagation path of the main OLR anomalies from Figure 3. (b) Anomaly map at day -10 . The contour interval is $4 \mathrm{~m}^{2} \mathrm{~s}^{-2}$, negative contours are dotted and the zero contour is omitted. Regions statistically significant at the 5\% level are shaded. (c) and (d) are as (a) and (b), but for primary MJ events (NABCD), and the contour interval is $8 \mathrm{~m}^{2} \mathrm{~s}^{-2}$.

features that are key to the generation of the MJO cannot be easily distinguished from secondary features that may not be fundamental to MJO generation. The distinction and separate analysis of primary MJ events, with no preceding MJO cycle, has allowed specific features to be unambiguously ascribed to the current MJ event, and precursor signals to be identified.

For primary MJ events beginning over the Indian Ocean, a precursor, stationary or standing, suppressed convective anomaly has been identified in the same region 15 days before the start of the events. The role of a standing component in the MJO has been debated previously. In an analysis of all MJ events, Zhang and Hendon (1997) found that no standing component could be identified. The results here suggest that a standing component is important for a subset of $\mathrm{MJ}$ events (the primary events). Due to the reduction in latent heat release, the suppressed convective anomaly has an associated negative mid-tropospheric temperature anomaly which destabilises the atmosphere to convection, leading the MJ event. The ultimate cause of the precursor suppressed convection is unknown and needs further investigation. A case-by-case study shows that the region of precursor suppressed convection is not present in all of the individual primary MJ events. Hence, some primary events do appear to be truly spontaneous and result from a random blow-up of convection, with a potential role for stochastic forcing, that then organises into an MJ event.
Anomalies of boundary-layer convergence, moisture, sea surface temperature, and subtropical synoptic activity are found in the successive MJ events, and during the later stages of the primary MJ events, but not preceding the primary MJ events. Hence, the theories that rely on these features, such as those of frictional moisture convergence, pre-moistening, air-sea interaction, and forcing by equatorward-propagating transients, do not appear to be fundamental to the spontaneous generation of the MJO. However, they are certainly not excluded from a role in the subsequent reinforcement and propagation of the MJO, once it is established.

In dynamical forecast models, future development of the MJO tends to have greater predictability when it is already established, compared to when it is initially absent (Jones et al., 2000). Additionally, all current empirical forecast models of the MJO rely on extrapolating forward a pre-existing MJO signal. Given the lack of a precursor signal in many variables, e.g. boundarylayer convergence, humidity, sea surface temperature, the potential to forecast the primary MJ events appears to be rather limited. However, it would be of interest to examine the skill of forecasts of primary MJ events when the precursor suppressed convection signal is present.

The general technique described here has not be exhaustively applied, and could profitably be used with other observational data and model output. A further application could be to use this technique to address the question of what makes a sequence of MJ events stop. 
'Terminal' MJ events can be defined as those that are not followed by another (successive) MJ event. These could be contrasted with 'preceding' MJ events, that do have a following (successive) MJ event, in a search for necessary conditions for a following successive MJ event. This seems an interesting line of enquiry. For MJ events that start over the Indian Ocean, there are 14 terminal events ('ABCDN'), compared to 89 preceding events ('ABCDA').

\section{Acknowledgements}

The interpolated OLR, NCEP reanalysis, MSU, and NOAA_OI_SST_V2 data were provided by the NOAA/ OAR/ESRL PSD, Boulder, Colorado, USA, from their web site at http://www.cdc.noaa.gov/. I thank Harry Hendon, Ian Renfrew, and an anonymous reviewer for comments that helped improve the manuscript.

\section{References}

Bantzer CH, Wallace JM. 1996. Intraseasonal variability in tropical mean temperature and precipitation and their relation to the tropical 40-50 day oscillation. J. Atmos. Sci. 53: 3032-3045.

Barnston AG, Livezey RE. 1987. Classification, seasonality and persistence of low frequency atmospheric circulation patterns. Mon. Weather Rev. 115: 1083-1126.

Bladé I, Hartmann DL. 1993. Tropical intraseasonal oscillations in a simple nonlinear model. J. Atmos. Sci. 50: 2922-2939.

Bond NA, Vecchi GA. 2003. The influence of the Madden-Julian oscillation on precipitation in Oregon and Washington. Weather Forecasting 18: 600-613

Flatau M, Flatau PJ, Phoebus P, Niiler PP. 1997. The feedback between equatorial convection and local radiative and evaporative processes: The implications for intraseasonal oscillations. J. Atmos. Sci. 54: 2373-2386.

Gill AE. 1980. Some simple solutions for heat-induced tropical circulation. Q. J. R. Meteorol. Soc. 106: 447-462.

Goswami BN. 2005. South Asian monsoon. Pp 19-62 in Intraseasonal variability in the atmosphere-ocean climate system, Lau WKM, Waliser DE (eds). Springer-Praxis: Heidelberg, Germany.

Hall JD, Matthews AJ, Karoly DJ. 2001. The modulation of tropical cyclone activity in the Australian region by the Madden-Julian oscillation. Mon. Weather Rev. 129: 2970-2982.

Hendon HH. 2000. Impact of air-sea coupling on the Madden-Julian oscillation in a general circulation model. J. Atmos. Sci. 57: 3939-3952.

Hendon HH. 2005. Air-sea interaction. Pp 223-246 in Intraseasonal variability in the atmosphere-ocean climate system, Lau WKM, Waliser DE (eds). Springer-Praxis: Heidelberg, Germany.

Hendon HH, Salby ML. 1994. The life cycle of the Madden-Julian oscillation. J. Atmos. Sci. 51: 2225-2237.

Hoskins BJ, Yang GY. 2000. The equatorial response to higher-latitude forcing. J. Atmos. Sci. 57: 1197-1213.

Hsu HH. 2005. East Asian monsoon. Pp 63-94 in Intraseasonal variability in the atmosphere-ocean climate system, Lau WKM, Waliser DE (eds). Springer-Praxis: Heidelberg, Germany.

Hsu HH, Hoskins BJ, Jin FF. 1990. The 1985/86 intraseasonal oscillation and the role of the extratropics. J. Atmos. Sci. 47: $823-839$.

Inness PM, Slingo JM. 2003. Simulation of the Madden-Julian oscillation in a coupled general circulation model. Part I: Comparison with observations and an atmosphere-only GCM. J. Climate 16: $345-364$.

Jones C, Waliser DE, Schemm JKE, Lau WKM. 2000. Prediction skill of the Madden and Julian Oscillation in dynamical extended range forecasts. Climate Dyn. 16: 272-289.

Kalnay E, Kanamitsu M, Kistler R, Collins W, Deaven D, Gandin L, Iredell M, Saha S, White G, Woollen J, Zhu Y, Chelliah M, Ebisuzaki W, Higgins W, Janowiak J, Mo KC, Ropelewski C, Wang J, Leetma A, Reynolds R, Jenne R, Joseph D. 1996. The NCEP/NCAR 40-year reanalysis project. Bull. Am. Meteorol. Soc. 77: 437-471.
Kemball-Cook SR, Weare BC. 2001. The onset of convection in the Madden-Julian oscillation. J. Climate 14: 780-793.

Kiladis GN, Weickmann KM. 1992. Circulation anomalies associated with tropical convection during northern winter. Mon. Weather Rev. 120: $1900-1923$.

Kiladis GN, Straub KH, Haertel PT. 2005. Zonal and vertical structure of the Madden-Julian oscillation. J. Atmos. Sci. 62: 2790-2809.

Knutson TR, Weickmann KM. 1987. 30-60 day atmospheric oscillations: Composite life cycles of convection and circulation anomalies. Mon. Weather Rev. 115: 1407-1436.

Lau WKM, Waliser DE (eds). 2005. Intraseasonal variability in the atmosphere-ocean climate system. Springer-Praxis: Heidelberg, Germany.

Liebmann B, Smith CA. 1996. Description of a complete (interpolated) OLR dataset. Bull. Am. Meteorol. Soc. 77: 1275-1277.

Lin H, Brunet G, Derome J. 2007. Intraseasonal variability in a dry atmospheric model. J. Atmos. Sci. 64: 2422-2441.

Maloney ED, Hartmann DL. 1998. Frictional moisture convergence in a composite lifecycle of the Madden-Julian oscillation. J. Climate 11: $2387-2403$

Matthews AJ. 2000. Propagation mechanisms for the Madden-Julian oscillation. Q. J. R. Meteorol. Soc. 126: 2637-2652.

Matthews AJ. 2004a. Intraseasonal variability over tropical Africa during northern summer. J. Climate 17: 2427-2440.

Matthews AJ. 2004b. The atmospheric response to observed intraseasonal tropical sea surface temperature anomalies. Geophys. Res. Lett. 31(14): L14107, DOI: 10.1029/2004GL020474.

Matthews AJ, Kiladis GN. 1999. The tropical-extratropical interaction between high-frequency transients and the Madden-Julian oscillation. Mon. Weather Rev. 127: 661-677.

Matthews AJ, Kiladis GN. 2000. A model of Rossby waves linked to convection over the eastern tropical Pacific. J. Atmos. Sci. 57: 3785-3798.

Mo KC, Paegle JN. 2005. Pan-America. Pp 95-124 in Intraseasonal variability in the atmosphere-ocean climate system, Lau WKM, Waliser DE (eds). Springer-Praxis: Heidelberg, Germany.

North GR, Bell TL, Cahalan RF, Moeng FJ. 1982. Sampling errors in the estimation of empirical orthogonal functions. Mon. Weather Rev. 110: 699-706.

Reynolds RW, Rayner NA, Smith TM, Stokes DC, Wang W. 2002. An improved in situ and satellite SST analysis for climate. J. Climate 15: $1609-1625$.

Salby ML, Hendon HH. 1994. Intraseasonal behaviour of clouds, temperature, and motion in the tropics. J. Atmos. Sci. 51: 2207-2224.

Shinoda T, Hendon HH, Glick J. 1998. Intraseasonal variability of surface fluxes and sea surface temperature in the tropical western Pacific and Indian Oceans. J. Climate 11: 1685-1702.

Spencer RW, Christy JR, Grody NC. 1990. Global atmospheric temperature monitoring with satellite microwave measurements: Methods and results 1979-84. J. Climate 3: 1111-1128.

Sperber KR, Slingo JM, Inness PM, Lau WKM. 1997. On the maintenance and initiation of the intraseasonal oscillation in the NCEP/NCAR reanalysis and the GLA and UKMO AMIP simulations. Climate Dyn. 13: 769-795.

Waliser DE. 2005. Predictability and forecasting. Pp 389-424 in Intraseasonal variability in the atmosphere-ocean climate system, Lau WKM, Waliser DE (eds). Springer-Praxis: Heidelberg, Germany.

Waliser DE, Lau KM, Kim JH. 1999. The influence of coupled sea surface temperatures on the Madden-Julian Oscillation: A model perturbation experiment. J. Atmos. Sci. 56: 333-358.

Wang B. 1988. Dynamics of tropical low frequency waves: An analysis of the moist Kelvin wave. J. Atmos. Sci. 45: 2051-2065.

Wang B. 2005. Theory. Pp 307-360 in Intraseasonal variability in the atmosphere-ocean climate system, Lau WKM, Waliser DE (eds). Springer-Praxis: Heidelberg, Germany.

Wheeler MC, Hendon HH. 2004. An all-season real-time multivariate MJO Index: Development of an index for monitoring and precipitation. Mon. Weather Rev. 132: 1917-1932.

Wheeler M, McBride JL. 2005. Australian-Indonesian monsoon. pp 125-174 in Intraseasonal variability in the atmosphere-ocean climate system, Lau WKM, Waliser DE (eds). Springer-Praxis: Heidelberg, Germany.

Woolnough SJ, Slingo JM, Hoskins BJ. 2000. The relationship between convection and sea surface temperature on intraseasonal timescales. J. Climate 13: 2086-2104.

Woolnough SJ, Slingo JM, Hoskins BJ. 2001. The organisation of tropical convection by intraseasonal sea surface temperature anomalies. Q. J. R. Meteorol. Soc. 127: 887-907. 
Yano JI, Blender R, Zhang C, Fraedrich K. 2004. 1/f-noise and pulselike events in the tropical atmospheric surface variabilities. $Q J$. $R$. Meteorol. Soc. 130: 1697-1721.

Zhang C. 2005. Madden-Julian Oscillation. Rev. Geophys. 43: RG2003, DOI: 10.1029/2004RG000158.
Zhang CD, Hendon HH. 1997. Propagating and standing components of the intraseasonal oscillation in tropical convection. J. Atmos. Sci. 54: $741-752$. 